Fanum

Sociológico

\section{Forum Sociológico}

Série II

$19 \mid 2009$

As Forças Armadas numa sociedade em mudança

\title{
O lugar do Dia da Defesa Nacional e a profissionalização das Forças Armadas: dilemas e desafios
}

José Manuel Resende

\section{(2) OpenEdition \\ Journals}

Edição electrónica

URL: https://journals.openedition.org/sociologico/103

DOI: 10.4000/sociologico.103

ISSN: $2182-7427$

Editora

CICS.NOVA - Centro Interdisciplinar de Ciências Sociais da Universidade Nova de Lisboa

\section{Edição impressa}

Data de publição: 1 junho 2009

Paginação: 11-24

ISSN: 0872-8380

\section{Refêrencia eletrónica}

José Manuel Resende, «O lugar do Dia da Defesa Nacional e a profissionalização das Forças Armadas: dilemas e desafios», Forum Sociológico [Online], 19 | 2009, posto online no dia 19 julho 2012, consultado o 30 março 2022. URL: http://journals.openedition.org/sociologico/103 ; DOI: https:// doi.org/10.4000/sociologico.103

Este documento foi criado de forma automática no dia 30 março 2022.

(c) CICS.NOVA 


\title{
O lugar do Dia da Defesa Nacional e a profissionalização das Forças Armadas: dilemas e desafios
}

\author{
José Manuel Resende
}

\section{Para que serve este ensaio sociológico sobre as conexões complexas entre a Profissionalização nas Forças Armadas e o Dia da Defesa Nacional?}

1 Este texto ensaia uma primeira e incompleta aproximação de uma questão mais vasta e complexa, tal como é retratada nas relações dilemáticas entre o propósito político de profissionalizar os novos contingentes militares, que são passíveis de ser recrutáveis através da acção directa, mas também mediada, das actividades ocorridas no Dia de Defesa Nacional, tal como está definido normativamente. Aliás, as diligências normativas delimitadas pela jurisdição são dispositivos fundamentais para se apreciar sociologicamente as concepções defendidas por quem as construiu, por um lado, mas também para analisar as questões de qualificação que aquelas mesmas orientações produzem nas Forças Armadas, através da introdução dos mecanismos que visam a sua profissionalização, utilizando o mesmo enfoque, do outro lado. Ora esta é uma das principais teses deste artigo.

2 Por outras palavras, a acção profissionalizante nas Forças Armadas vai introduzir novas questões no quadro da qualificação dos jovens que decidem aceder a cada um dos três ramos daquelas forças. Essa acção qualificante não os qualifica só do ponto de vista profissional, através da realização de cursos de profissionalização, de modo a dotá-los de mais qualificação profissional, ou de uma qualificação mais ajustada para uma entrada futura no mercado de trabalho depois de terminado o seu tempo de permanência nas Forças Armadas. A profissionalização das Forças Armadas faz recair em cada uma das forças que a compõem uma nova configuração mercantil, que até então não era visível, uma vez que a obrigatoriedade na conscrição anulava um dos 
princípios que dá forma a esta relação em termos mercantis: a liberdade de decisão de cada indivíduo para se alistar, usando para esse recrutamento a figura do contrato ou de uma entrada voluntária.

3 Para dar corpo a estas transformações nas Forças Armadas a tutela política do Ministério da Defesa Nacional, como representação estatal neste domínio, introduz na política orientadora deste ministério duas novas figuras jurídicas que são relevantes para este ensaio sociológico. Estas duas figuras são dois dispositivos que configuram muitos dos dilemas e desafios que são lançados ao desejo político de as Forças Armadas se profissionalizarem, indo assim ao encontro das aspirações dos jovens politicamente enquadrados nas juventudes partidárias. Quais são as figuras referenciadas no artigo e que tentam abarcar tais desideratos, por um lado, mas que concomitantemente levantam determinados dilemas? A primeira figura está corporizada no Dia de Defesa Nacional. A segunda figura é traduzida no novo conceito estratégico de Defesa Nacional.

o Dia de Defesa Nacional é um momento marcante no processo de profissionalização em vista porque o seu principal objectivo é mostrar o que são hoje as Forças Armadas, as suas características próprias e as suas potencialidades no presente e no futuro, a todos os jovens que obrigatoriamente por ali têm de passar um dia de acordo com um programa e um calendário previamente definidos. Apesar de o DDN se assumir como um cartão-de-visita relativamente a cada um dos três ramos das Forças Armadas, esta nobre tarefa não esgota a sua missão. Uma outra tarefa é para nós mais interessante destacar, pois prende-se com o carácter mobilizador que se pretende imprimir a este evento. Na verdade, o DDN é um dispositivo jurídico e estatal que diligencia, junto dos jovens, um conjunto de informações susceptíveis de os levar a tomar a decisão "livre" e racional, de serem sujeitos ao recrutamento militar. Ora para que esse envolvimento se verifique o DDN apresenta-se como um espaço de promessas quanto aos benefícios e recompensas que os jovens podem usufruir se tomarem como projecto de vida, mesmo que transitório, a sua presença num dos três ramos das Forças Armadas, durante um determinado período de tempo. Contudo, por vezes existem desajustamentos fortes entre aquilo que se oferece e aquilo que se procura, uma vez que as Forças Armadas também se dedicam a trabalhar num projecto de Socialização Política e Cívica junto desta população num "governo por regras" completamente distinto de outros projectos semelhantes exercitados em outras instâncias estatais, como é o caso da escola.

o conceito estratégico de Defesa Nacional é um documento que reorienta as acções preferenciais das Forças Armadas, quer do ponto de vista interno, quer do ponto de vista externo. Além da importância assumida pelo planeamento estratégico, existem outros dois princípios que se constituem como o norte orientador, quer das suas actividades, quer também do envolvimento dos seus quadros, em particular dos jovens recrutas, nessas mesmas actividades. Os princípios da eficiência e da eficácia, medidores preferenciais nas relações contratuais das empresas, entram subitamente numa organização que habitualmente assentava a sua actividade no princípio cívico, uma vez que a realização das suas tarefas propendia para (como ainda visa) a representação e a defesa de uma comunidade política inscrita num Estado-Nação. Por outro lado, a acção das Forças Armadas, não menorizando a sua actuação a nível nacional, não deixa de deslocar parte da sua atenção para o palco internacional, cooperando com outras forças em desafios levantados pela (e decorrentes da) globalização ou mundialização das relações comerciais, industriais, dos fluxos humanos no quadro das grandes movimentações migrantes, na resposta a grandes calamidades e 
catástrofes ambientais, às acções do terrorismo internacional, sem esquecer as relações políticas e militares no quadro dos compromissos do País face à União Europeia e à NATO.

6 Finalmente, e seguindo o mesmo raciocínio, no último ponto não deixamos de levantar alguns dilemas e controvérsias que podem ser suscitadas pelas relações complexas entre a globalização e o projecto de modernidade liberal alargada, com incidências quer no processo de profissionalização das Forças Armadas, quer indirectamente no Dia de Defesa Nacional, quer ainda nas vivências experimentadas e monitorizadas pelos jovens que acedem aos territórios das Forças Armadas, através do seu recrutamento. De facto, o processo de individuação em curso nas sociedades modernas, acentuado pela elevação das qualificações escolares, não só pode intervir nas decisões relativas ao recrutamento, como pode acentuar as assimetrias, não só entre as probabilidades condicionais de os actores se envolverem no recrutamento, segundo os graus de qualificação, em cada um dos três ramos das Forças Armadas, como pode igualmente ter uma grande interferência na decisão dos mais qualificados em não aderir à ideia de aceder à profissão de militar.

7 As discussões e debates em torno da multiculturalidade, da interculturalidade, mas também em torno do género e das orientações sexuais levantam também outros problemas, agora do lado dos valores da autenticidade e da singularidade. Havendo perante a lei a igualdade e a equivalência de tratamento de todos os indivíduos naquilo que respeita ao acesso às Forças Armadas, o cumprimento integral desta orientação geral não deixa de provocar internamente outros questionamentos e debates, quer nas suas políticas de formação, quer nas suas políticas de promoção, quer no domínio das inter-relações e modos estilizados de vida.

\section{O Dia de Defesa Nacional no quadro da nova configuração assumida pela Lei de Serviço Militar}

\section{O novo suporte jurídico e normativo do DDN}

8 A Lei $n .$. 174/99 de 21 de Setembro pôs termo ao serviço militar obrigatório em Portugal. Indo ao encontro daquilo que já se tinha passado em diversos países do mundo inteiro (de uma forma faseada entre os anos 60 e os anos 90 do século passado), mas em particular nos países integrados na União Europeia e na Aliança Atlântica (NATO), o Governo português transforma em lei um dos objectos de discussão política que mais se debateu, sobretudo através das tomadas de posição avançadas pelas estruturas partidárias dos grupos etários juvenis ligados quer ao Partido Socialista, quer ao Partido Social-Democrata. A partir da decretação deste diploma oficial, nas Forças Armadas tanto a conscrição obrigatória total e efectiva como a conscrição praticada "às sortes" foram substituídas por outras modalidades de serviço efectivo prestado ao Estado no âmbito militar, a saber:

- Serviço efectivo dos quadros permanentes que engloba o conjunto dos corpos militares que se encontram continuamente vinculados ao conjunto das Forças Armadas;

- Serviço efectivo por regime de contrato que abarca o conjunto dos indivíduos ligados aos diferentes corpos das Forças Armadas através de uma vinculação contratual que não pode ultrapassar o número de anos oficialmente determinado (6 anos); 
- Serviço efectivo por regime de voluntariado que compreende o conjunto de indivíduos que por um período de 12 meses decide voluntariamente fazer parte dos corpos das Forças Armadas;

- Serviço efectivo decorrente de convocação ou mobilização geral e obrigatória a ser determinado política e publicamente em situações extremas, quer para responder a ofensivas militares externas ao País, quer para responder a agressões militares externas e em massa (quer do ponto de vista do contingente militar, quer do ponto de vista territorial) de outras forças militares organizadas em blocos ou alianças hostis às alianças políticas (por exemplo, a União Europeia) e militares (Aliança Atlântica) a que o País pertence de pleno direito.

9 É preciso notar que a nomeação e especificação de cada um destes quatro tipos de serviços oferecidos pelas Forças Armadas estão em correspondência quer com os princípios gerais de organização militar, quer com as missões decretadas pela Lei n.. 111 de 29 de Agosto de 1991. Desta forma os três ramos das Forças Armadas e as configurações profissionais saídas dos regimes outorgados pelo Estado, além de obedecerem "aos órgãos de soberania competentes, nos termos da Constituição e da lei", inserem-se "na administração directa do Estado, através do Ministério da Defesa Nacional" (Lei n.o 111/91 de 29 de Agosto). Por outro lado, ao conjunto das forças militares integradas nas Forças Armadas são cometidas as seguintes missões:

- Assegurar a defesa militar contra qualquer agressão ou ameaça exterior;

- Satisfazer, no âmbito militar, os compromissos internacionais;

- Colaborar em tarefas relacionadas com a satisfação das necessidades básicas e a melhoria da qualidade de vida das populações, inclusivamente em situações de calamidade pública que não justifiquem a suspensão do exercício de direitos;

- Respeitar as emanações definidas pelo Conselho Superior de Defesa Nacional mediante proposta do Ministro da Defesa Nacional e sob proposta do Conselho de Chefes de EstadoMaior;

- Respeitar as condições de emprego das Forças Armadas definidas por lei que regulam as situações de estado de sítio ou estado de emergência (artigo n.. 2 da Lei n.ำ 111/91 de 29 de Agosto, p. 4491).

$10 \mathrm{Na}$ verdade, se as missões acima identificadas permitem reconhecer quais as delimitações das acções gerais empreendidas pelas Forças Armadas, os princípios gerais de organização militar especificam com mais detalhe o seu enquadramento jurídico e legal. Assim, de um lado "a organização das Forças Armadas tem como objectivos essenciais o aprontamento eficiente e o emprego operacional eficaz das forças no cumprimento das missões atribuídas", mas por outro lado a mesma organização "regese por princípios de eficácia e racionalização", devendo, designadamente, garantir:

- A melhoria da relação entre a componente operacional do sistema de forças e a sua componente fixa ou territorial;

- A redução do número de escalões e órgãos de comando, direcção ou chefia;

- A articulação e complementaridade entre os ramos, evitando duplicações desnecessárias e criando órgãos de apoio a mais de um ramo sempre que razões objectivas o aconselhem;

- A correcta utilização do potencial humano, militar ou civil, promovendo o pleno e adequado aproveitamento dos quadros permanentes e assegurando uma correcta proporção e articulação entre as diversas formas de prestação de serviço efectivo (artigo n.․ 4 da Lei n.o 111/91 de 29 de Agosto, p. 4491). 


\section{Do enquadramento às potencialidades proporcionadas pela jurisdição}

11 Neste sentido, a tipificação e ordenação dos serviços arregimentados e oferecidos pelas Forças Armadas, definidos pela Lei n.. $174 / 99$ de 21 de Setembro, clarificam perante o cidadão em geral e o cidadão que completa 18 anos em cada ano civil, em particular, o grau de importância atribuída pela instância estatal a cada um destes regimes. Na verdade tal tipificação cria em cada um três ramos das Forças Armadas uma fragmentação do seu mercado interno profissional, tendo em conta por um lado as particularidades e constrangimentos associados a cada forma de recrutamento relacionada com o tipo de serviço assinalado em que a variável do tempo de vinculação desempenha um papel crucial, mas tendo em conta por outro lado os distintos trabalhos mais corporais ou técnicos ligados às missões definidas tanto pela hierarquia política como pela hierarquia militar, de forma coordenada e convencionada, mas sempre de acordo com a lei vigente.

12 Contudo, o entendimento do Estado sobre as modalidades a pôr em prática no sentido de dar a conhecer os novos propósitos das políticas públicas de Defesa Nacional não pode esgotar-se na sua divulgação através da maquinaria cultural de jurisdição (Abbott, 1988) que suporta a sua actividade. Na verdade toda a actividade jurídica ao serviço do Estado é um suporte indispensável, quer para a acção das elites políticas que num dado momento governam ou regulam a actividade do governo, quer para a acção dos seus funcionários e corpos especiais, quer ainda para os restantes cidadãos.

13 Assim, o quadro jurídico referente ao Dia de Defesa Nacional informa, clarifica, guia, tipifica, classifica e delimita os contornos de acção do objecto que está a ser sujeito ao exame político na sua forma jurídica. E não obstante os efeitos desse trabalho de enquadramento, a referida maquinaria cultural de jurisdição (ibidem) não deixa de se apresentar como um dispositivo de "investimento de forma" (Thévenot, 1986) assinalável, mesmo no que diz respeito a estas actividades que conferem novas orientações ao processo de recrutamento militar.

14 Desta forma, a normatividade definida por estes documentos é fundadora de dois regimes de acção de envolvimento distintos, mas complementares (Boltanski e Thévenot, 1991; Thévenot, 2006). Por um lado, o seu quadro jurídico fornece elementos decisivos para os cidadãos com mais de 18 anos planearem uma eventual entrada nas Forças Armadas, beneficiando dos apoios estabelecidos pela lei, mas cumprindo igualmente os seus deveres ali referenciados. Este regime de envolvimento da acção em plano torna viável a utilização de determinados dispositivos, definidos pela lei, que podem ser mobilizados para a criação, em cada um dos contratados e voluntários, de um projecto que vise não só orientar a sua experiência militar e profissional num dos ramos das Forças Armas, mas também preparar de modo ajustado a sua futura saída para o mercado de trabalho menos protegido pelo Estado.

15 Por outro lado, as promessas ali indicadas e ligadas aos referidos direitos transformados em benefícios podem também revelar os seus obstáculos, sobretudo quando as expectativas criadas são a expressão de práticas de desencanto ou de insatisfação por parte daqueles que decidem entrar nas Forças Armadas utilizando estes novos dispositivos regulamentados pela lei. Neste caso, as eventuais 
manifestações expressas em público constituem orientações práticas no âmbito do regime de envolvimento da acção em prol da justiça ou do justo.

Assim, o reconhecimento entre aquilo que resulta da lei e aquilo que efectivamente beneficiou com a sua experiência militar pode desencadear no contratado e no voluntário percepções ajustadas sobre o injusto e o injustificado, uma vez que experencia, no quotidiano, uma distância entre o que é prometido e a sua realização concreta. As manifestações críticas que são geradas por este desencontro deslocam o regime de envolvimento de acção para os "mundos" da distribuição daquilo que os actores concebem como (in)justo tendo em conta o seu grau (desigual) de conhecimento dos benefícios referidos no quadro legal.

-sentido, se o enquadramento jurídico constitui um dispositivo para o estabelecimento de um "governo por regras" para os actores inseridos no quadro institucional - neste caso as Forças Armadas -, revela-se igualmente como um suporte que potencia a crítica quando a experiência de alguns destes mesmos actores é construída a partir de múltiplas situações de privação relativa (Maravall, 1972).

18 É tendo em conta esta nova configuração de carácter político (no sentido do público), traduzida também num novo enquadramento jurídico, que o Estado, através do trabalho político de mobilização a realizar pelo Ministério da Defesa Nacional, com a plena cooperação e solidariedade das Forças Armadas (em particular das suas chefias), mas também com o apoio de todo um outro conjunto de instituições estatais, instaurou um dia nacional dedicado à Defesa Nacional e às suas forças. Além de ter por tarefa a sensibilização dos jovens para a sua disponibilidade voluntária ou contratual de servir o País através da sua incorporação num dos ramos constitutivos das Forças Armadas, este Dia de Defesa Nacional contribui para difundir as linhas de força incluídas no conceito estratégico de defesa nacional, as diversas missões adstritas ao Exército, Força Aérea e Marinha, assim como os incentivos associados a cada um dos regimes de serviço estipulados por lei.

Uma vez que o Dia de Defesa Nacional é hoje considerado como o meio privilegiado do Estado para a efectivação do recrutamento militar, através dos regimes de voluntariado ou de contrato, o Ministério de Defesa Nacional através da Direcção Geral de Pessoal e Recrutamento Militar conta para a sua prossecução com apoio de um conjunto diversificado de instituições públicas. Entre as tarefas de natureza administrativa, de ordenação, de classificação e codificação cometidas a certas instituições nomeadas no Regulamento da Lei do Serviço Militar (Decreto-Lei n. 289/2000 de 14 de Novembro), compete aos estabelecimentos de ensino públicos e privados através da celebração de protocolos com o Exército - "enquanto agente de recenseamento militar" - e com os outros ramos das Forças Armadas - "enquanto executantes do recrutamento normal" (ibidem, 6428) - o desenvolvimento de um conjunto de actividades no sentido "de sensibilizar os jovens para a temática da defesa nacional e de divulgar o papel das Forças Armadas" (ibidem). Por outro lado, e ainda no âmbito da publicitação pública desta mesma temática, assim como das actividades e missões específicas ligadas a cada um dos três ramos das Forças Armadas, o Ministério da Defesa Nacional conta com o trabalho de "divulgação tempestiva através dos órgãos de comunicação social de expressão nacional e regional" dos locais e data de realização do Dia de Defesa Nacional (ibidem, 6429).

20 Contudo, a obrigatoriedade de participar no Dia de Defesa Nacional não é ainda universal, uma vez que só aos jovens do género masculino é que tal presença é 
estritamente obrigatória. Apesar de se ter facultado a incorporação nos três ramos das Forças Armadas das jovens, a sua presença neste evento só acontece por vontade expressa de cada uma delas. Presentemente esta situação tende a alterar-se, prevendose para o ano de 2010/2011 a presença obrigatória no DDN de todas as jovens com idade de 18 anos.

\section{Um olhar etnográfico pelo Dia de Defesa Nacional: os objectos como tradutores da acção}

21 O Dia de Defesa Nacional ocorre entre o mês de Outubro e o mês de Maio do ano seguinte e está previsto desenvolver as suas actividades numa unidade militar pertencente a cada um dos três ramos das Forças Armadas. Distribuídas pelas diferentes regiões, estas unidades recebem estes jovens a partir de um plano previamente estabelecido por uma comissão nomeada pela Direcção Geral de Pessoal e Recrutamento Militar, com a colaboração estreita de cada um dos três ramos das Forças Armadas.

Chegados aos locais e datas previstas com o apoio logístico garantido pelo Estado, uma vez que são transportados por autocarros desde as Câmaras Municipais até às unidades militares, estes jovens são encaminhados para pavilhões existentes ou construídos para o efeito com a finalidade de serem identificados. Seguidamente são distribuídos por duas salas contíguas onde são convidados a participar activamente, durante todo esse dia, nos diferentes módulos em que se apresentam de uma forma organizada e ordenada os diferentes suportes de informação escrita e iconográfica previamente concebidos e preparados pela entidade promotora deste evento.

23 Através de fotografias expostas em painéis distribuídos nos pontos de recenseamento, mas também nas salas, os jovens são logo confrontados com as imagens que de certa forma identificam a singularidade e especificidade de cada um dos três ramos das Forças Armadas. Assim, tais imagens representam, por um lado, as potencialidades tecnológicas de cada uma destas forças e por outro lado a objectivação desses meios como suportes materiais indispensáveis para a realização das missões associadas ao Exército, Força Aérea e Marinha, e que dão corpo às linhas de intervenção das Forças Armadas no quadro do actual conceito estratégico de defesa nacional.

O trabalho de "investimento de forma" (Thévenot, 1986) associado a cada um dos três ramos das Forças Armadas não começa nem acaba com esta exposição fotográfica. Para os jovens representantes de cada um dos corpos militares - do género feminino e masculino - estão disponíveis outros suportes escritos e de imagem com o propósito de os apoiarem na explicação do actual conceito estratégico de defesa nacional, dos novos perfis de serviço militar e correlativos incentivos, das missões em que as Forças Armadas se encontram empenhadas de acordo com os compromissos firmados no âmbito quer da Nato, quer da União Europeia, quer ainda das Nações Unidas e de outras questões eventualmente levantadas pelos participantes. Tendo em conta os intentos deste dia, todas as imagens dos filmes, assim como as explicações dadas a propósito das mudanças ocorridas no serviço militar, em particular sobre o conjunto de incentivos conectados a cada um dos regimes de serviço tipificados, seguidas de debates mais ou menos participados (dependendo das capacidades de liderança e de mobilização demonstradas pelos animadores destas sessões), e para além do esclarecimento dado com todo o pormenor, indo ao encontro das questões apresentadas, a maior expectativa 
é saber qual vai ser a real adesão manifestada pelos jovens presentes no final deste evento.

Estas sessões não são contínuas. São intercaladas com intervalos, com um almoço oferecido aos presentes, mas também com sessões de trabalho em que os militares do serviço efectivo dos quadros permanentes apresentam uma (ou várias) das actividades especificamente identificadas com cada uma das unidades militares onde se desenrola este acontecimento. Correspondendo à iniciativa e imaginação das equipas responsáveis pela apresentação e divulgação das tarefas constantes de cada uma destas unidades, estas sessões contribuem para confirmar junto dos jovens assistentes as especificidades dos objectivos, das finalidades e das missões conferidas a cada um dos três ramos das Forças Armadas. Neste sentido a singularidade de cada um destes corpos é garantida pela observação ao vivo dos treinos das suas forças ou da utilização dos meios tecnológicos existentes ou ainda pela possibilidade de verem por dentro como funciona um vaso de guerra da Marinha, ou de numa base área assistirem ao vivo às potencialidades técnicas e estratégicas de um avião de combate.

Por fim, já no final do dia espera-se aferir o número de adesão dos jovens presentes aos novos regimes de serviço referenciados na Lei de Serviço Militar. Consoante o número de pedidos ali deixados, e a sua distribuição tanto ao nível dos regimes de serviço escolhidos como ao nível da tradução daquela selecção num dos ramos das Forças Armadas, assim é interpretado o grau e a intensidade da resposta deste sector da sociedade civil relativamente às novas configurações assumidas pelo sector militar. Contudo, entre este tempo de manifestação de intenções já de certo modo objectivadas pelo facto de terem deixado registado esse desejo e o tempo em que tal vontade é objectivamente manifestada por intermédio do efectivo recrutamento nas Forças Armadas decorre uma outra temporalidade com um certo grau de indeterminação e incerteza.

\section{Os desafios colocados à Defesa Nacional e às Forças Armadas com a implementação do novo Serviço Militar: dos processos de recrutamento militar ao conceito de estratégia de defesa nacional}

A passagem do serviço militar obrigatório - seja qual for a adequação entre o seu enquadramento jurídico e as determinações práticas definidas pelas instâncias superiores em relação aos mecanismos e modalidades de recrutamento - para um serviço militar assente na base da constituição de Forças Armadas profissionalizadas vai requerer um exame prévio das instâncias superiores e dos especialistas, quer sobre o número de indivíduos ao serviço de cada um dos corpos militares no âmbito de cada um dos três ramos das Forças Armadas, quer sobre o perfil mais adequado dos indivíduos para se ajustarem às tarefas e missões destinadas a esses mesmos corpos e aos ramos onde estão integrados. Isto significa que o princípio universal subjacente ao serviço militar obrigatório é substituído pelo princípio da eficácia e da eficiência agora presente de forma mais vincada na nova configuração jurídica associada ao serviço militar aprovado no final dos anos 90 do século passado.

o lugar central que o planeamento vai assumir na nova ordem militar em curso está intimamente ligado, por um lado, à crescente tese da necessidade de haver forças 
militares cada vez mais profissionalizadas, mas está também conectada, por outro lado, com a importância crescente que passa a existir entre as lógicas dos fluxos das procuras e das ofertas nos mercados de emprego cada vez mais fragmentados e as lógicas das procuras e das ofertas militares presididas por princípios que nem sempre se encontram ajustados aos princípios dos mercados de emprego ligados a outros sectores da actividade económica. Por outras palavras, as lógicas ligadas ao princípio da eficácia e da eficiência das Forças Armadas não são inteiramente decalcáveis das lógicas associadas ao princípio da eficácia e eficiência do "mundo industrial" tal como concebido pela Filosofia Política (Boltanski e Thévenot, 1991).

Na verdade, o "mundo industrial" que se retira das reflexões filosóficas sobre as sociedades modernas, urbanas e industrializadas que emergem de forma cada vez mais sólida no século XIX faz a ligação entre o princípio da eficácia e da eficiência com a racionalidade associada à produção e produtividade fabril. Face a mercados que tendem a mundializar-se (independentemente das barreiras alfandegárias entretanto criadas e que dificultam o livre acesso das mercadorias), toda a actividade industrial começa a ter de pontuar o seu trabalho na base da produção em maior quantidade, mas com o menor número de despesas, uma vez que a competição entre empresas adquire cada vez mais um lugar de destaque, quer nas lógicas de trabalho fabril, quer nas lógicas mercantis.

Noutros termos, as lógicas incorporadas no trabalho eficaz e eficiente vão ganhando terreno ao longo do tempo, quer no universo empresarial, quer no universo político, uma vez que parecem ser os valores mais adequados, sobretudo no espírito dos empreendedores, para responder às lógicas competitivas que florescem no mercado de trabalho e no mercado das mercadorias. Neste sentido, o sistema de produção económica, de um lado, e a fabricação do produto final, do outro lado, não podem ser completamente autónomos da lógica competitiva do mercado que dá um contributo decisivo para a busca do lucro, optimizando ao máximo os custos de produção.

Por outro lado, as transformações operadas no espírito do capitalismo e nos princípios orientadores que guiam as acções dos gestores emergentes a partir dos anos 70 do século XX, com a introdução das lógicas centradas no projecto e na flexibilização da mão-de-obra (Boltanski e Chiapello, 1999; Boltanski, 2001), também não se mostram totalmente adequadas às lógicas da eficácia e da eficiência militar no quadro do novo Serviço Militar. De facto, as mudanças ocorridas nos mercados de emprego, nas modalidades de gestão dos recursos humanos das empresas, mas também as alterações geradas nos locais de trabalho a partir da importância assumida pela cultura de empresa, apesar de não terem o mesmo impacto em todos os sectores de actividade económica, criam concepções e entendimentos muito distintos daqueles que estão a ser introduzidos no universo militar.

32 Por outras palavras, as novas e velhas formas de recrutamento da mão-de-obra qualificada e não qualificada nos diferentes sectores de actividade económica não são similares aos processos de recrutamento militar, mesmo quando tal recrutamento visa captar uma mão-de-obra muito qualificada. Desta forma, os perfis profissionais mais ou menos ajustados aos mercados de emprego ou às expectativas dos empregadores não são totalmente compatíveis com os perfis profissionais esperados e desejados nos contextos militares.

33 À partida, tais desajustamentos começam por fazer-se sentir nos juízos construídos, quer sobre a noção de profissão de militar, quer sobre a noção de mercado militar. Na verdade, tanto a noção de profissão associada às actividades militares como o 
funcionamento do mercado das forças em armas apresentam características específicas e singulares, em que a autonomia relativa interna se apresenta mais mitigada.

$\mathrm{Na}$ verdade, os constrangimentos presentes nos processos de recrutamento militar deslocam-se de dentro do específico universo de cada ramo das Forças Armadas para os espaços políticos nacionais e internacionais. Desta forma, as condicionantes ligadas, por um lado, à definição das linhas estratégicas de actuação das Forças Armadas e, por outro lado, às oscilações da procura e da oferta dos contingentes a recrutar para cada um dos corpos e ramos destas mesmas forças militares escapam ao total e directo controlo das chefias e especialistas que trabalham dentro deste sector ao serviço do Estado (Evetts, 2003).

A partilha existente entre as orientações militares e as orientações políticas internas e externas verificadas na definição do conceito de estratégia de defesa nacional é um aspecto já presente no próprio enquadramento jurídico publicado na Resolução do Conselho de Ministros n. 6/2003 de 20 de Janeiro. Neste sentido, a relativa deslocação do controlo directo e total da definição destes conceitos centrais para a delimitação da maquinaria cultural da jurisdição das Forças Armadas (Abbott, 1988) aparece objectivada neste documento, por duas razões fundamentais.

Por um lado, por razões de natureza política. Os processos e condições de legitimação dos actos e formas de actuação das Forças Armadas estão dependentes dos processos e condições ligados à legitimidade das forças políticas, quer a legitimidade conferida pelo peso específico de cada partido político no Parlamento, quer a legitimidade fundada pelo poder e autoridade exercidos pelo Chefe do Estado, estando estas duas formas legítimas do exercício do controlo político consignados e limitados pela Carta Constitucional Portuguesa.

Mas, por outro lado, esta mesma natureza política interna que fundamenta a legitimidade atrás mencionada está também sujeita a outros fundamentos de legitimidade política agora ancorados em diversas convenções internacionais acordadas e assinadas pelos representantes políticos nacionais. Tais convenções firmam compromissos políticos da comunidade política nacional, quer em relação a novas formas de associação e solidariedade política intergovernamental e supranacional - tal como acontece com o espaço político europeu constituído pela União Europeia ou tal como ocorre com a integração do País na Organização das Nações Unidas -, quer em relação à aliança política e militar estabelecida com a Nato, quer ainda em relação a outras formas de associação política e de solidariedade distintas das anteriores porque justificadas por outros princípios, funções e finalidades de actuação, como acontece, por exemplo, com a CPLP.

38 As novas inferências estabelecidas pelo Estado português, seja relativamente aos espaços mais alargados de intervenção das Forças Armadas, seja relativamente às novas modalidades de intervenção que produzem efeito na reorganização das diferentes forças que compõem os três ramos militares, seja ainda a necessidade de repensar formas de intervenção militar resultantes das crises políticas nacionais ou estrangeiras provocadas, entre outras razões, por movimentos políticos extremistas ou por calamidades naturais, resultam dos diagnósticos realizados por diferentes instâncias e especialistas nacionais e estrangeiros. Ora o novo enquadramento institucional a partir do qual é pensado o conceito de estratégia de defesa nacional parte justamente de uma primeira identificação tanto dos riscos que tornam mais vulneráveis os Estados 
modernos como dos espaços geopolíticos onde tais riscos tendem a espoletar com mais frequência e intensidade.

Além de determinar na carta geográfica planetária as regiões potenciais de onde emergem os "riscos de separatismos e conflitos étnicos, religiosos e fronteiriços, fundamentalismos ou migrações em massa", o enfraquecimento das funções de controlo e regulação dos Estados destas zonas do globo "torna crescentes as ameaças ligadas ao terrorismo, ao narcotráfico, ao tráfico de pessoas e ao crime organizado", sem esquecer o aumento dos "riscos de proliferação de armas de destruição de massa e de uso indevido de novas tecnologias, bem como a diminuição de garantias de manutenção e controlo de equipamentos e material nuclear, radiológico, químico e biológico" (Resolução do Conselho de Ministros n. 6/2003, 280). Se a classificação e ordenação destes riscos dão corpo aos alertas produzidos por diferentes especialistas, em particular os sociólogos que há muito chamam a atenção para as novas configurações políticas e económicas desenhadas nas sociedades modernas e que decorrem dos problemas provocados não só pelo modelo industrial, mas também pelo modelo das relações pouco reguladas entre a ciência, tecnologia e indústria, os riscos que resultam "da desregulação ambiental e ecológica e da gestão dos recursos naturais, nomeadamente os hídricos e os energéticos" (ibidem), reforçam a incerteza e a indeterminação em todo o planeta, mobilizando países e organizações internacionais para um estado permanente de alerta muito potenciado pela intervenção cada vez mais extensiva dos meios de comunicação social, em particular da comunicação televisiva.

40 A partir deste já extenso diagnóstico é ainda possível referir outros factores que influenciam e condicionam as relações entre os Estados e as regiões. Dos factores de natureza económica - assimetrias regionais crescentes de desigualdade no desenvolvimento económico com repercussões nas desigualdades de acesso a bens comuns que fazem parte das esferas de justiça - aos factores resultantes das redes de informação e de interactividade potenciadas pelos meios de comunicação "clássicos" e também pelas novas formas de comunicação geradas pela mudança tecnológica (entre outros, identificam-se a rede de telemóveis e a Internet), também os riscos provocados pela aplicação do produto da ciência fundamental (em diferentes áreas do saber) na tecnologia ou ainda os crimes económicos resultantes da corrupção, tráfico de influência e da lavagem do dinheiro contribuem para "definir um conceito alargado de segurança que, continuando a integrar os objectivos mais tradicionais dos Estados defesa do território e da soberania -, confere atenção acrescida a uma filosofia preventiva e a uma visão global da evolução dos focos de insegurança internacional e das crises que deles decorrem, com o intuito de as prevenir e limitar, evitando o seu desenvolvimento para formas agravadas de conflitualidade" (ibidem).

41 Neste sentido, a extensão do conceito de estratégia de defesa nacional que ultrapassa o território e a soberania nacionais acaba por conferir, tal como acontece a outros domínios das sociedades humanas, um lugar de destaque à noção de rede (Boltanski, 2001) e à necessidade de esta funcionar de forma harmoniosa e equilibrada de forma a atingirem-se patamares elevados de controlo, regulação e segurança sem pôr em causa as liberdades e os direitos fundamentais dos indivíduos modernos (Wagner, 1996). Sem deixar de se prescindir em toda a extensão territorial, e até simbólica, da noção de soberania nacional, o alargamento das formas de actuação militares para responder aos desafios e perigos assinalados acaba por criar uma permanente tensão entre defesa de 
interesses gerados ora dentro ora fora do País, o mesmo é dizer-se entre a defesa de interesses particulares e interesses gerais.

A esta tensão é possível adicionar uma outra que já atrás é mencionada sem se lhe dar o destaque merecido. Essa pressão advém das controvérsias geradas nas sociedades modernas entre as retóricas presentes nas práticas gramaticais em que assentam as liberdades cívicas e políticas - alimentadas nos debates públicos - e as retóricas inscritas nas práticas gramaticais favoráveis à regulação e auto-regulação - também difundidas nos debates políticos.

No quadro desta equação entre a liberdade e a disciplina (ibidem) as ambiguidades tendem a ser crescentes, nomeadamente em momentos políticos complexos em que as Forças Armadas são levadas a intervir para repor a ordem democrática ou a soberania de um Estado, seja o nosso ou seja outro, agora num plano transnacional. Por vezes as aç̧ões violentas que estão vinculadas aos princípios da reposição da ordem pública apresentam-se à vasta audiência que as observa através dos canais de televisão numa forma híbrida - entre a aceitação e a suspeição do seu exagero - ou na forma de aplauso, quando a adesão é grande, ou ainda na forma de crítica, por considerarem uma intervenção excessiva e que põe em causa a liberdade dos indivíduos desses países. Quanto mais morosa for a intervenção, maior é o desgaste da opinião pública em relação à sua presença nestas geografias pautadas pela intervenção com fins humanitários ou de reposição da soberania de um Estado.

Desta forma assiste-se, em virtude das ambiguidades assinaladas, e no âmbito das noções de Estado-Nação e de soberania, sem se prestar muita atenção pública, a um processo de transferência entre dois tipos de particularismos e dois tipos de universalismos que decorrem do destaque que assume a integração planetária (Elias, 1990) e o conceito de comunidade humana (Boltanski e Thévenot, 1991). Apesar de não haver uma evolução continuada e linear nos processos civilizacionais, os mecanismos de regulação política tendem a ser cada vez mais pensados do ponto de vista global, por intermédio da intervenção das Nações Unidas no seu conjunto, ou por um conjunto de países sob delegação desta organização internacional.

Desta forma, os anteriores particularismos individuais que se confrontavam com os interesses gerais de uma comunidade política nacional no século XIX e em grande parte do século passado são substituídos pelos particularismos nacionalistas quando estes não respondem aos desafios políticos de colocarem parte das suas forças (as mais profissionalizadas) ao serviço de missões humanitárias, da regulação de conflitos armados, ou ainda da consolidação da paz territorial. Ora esta operação política, e sequencial, entre categorias e formas de categorização espacial - do plano individual à comunidade local, de um lado, da comunidade nacional ao espaço regional e mundial, do outro lado - está a desenrolar-se em simultâneo com a formação de ambientes sociais nacionais e mundiais em que as noções de risco, de alerta e de responsabilização individual constantes parecem sobrepor-se à noção das promessas de se constituírem sociedades mais seguras, solidárias e justas.

Noutros termos, nas sociedades modernas, as noções de risco (Beck, 2001; Beck, Giddens e Lash, 2000), de ambivalência (Bauman, 1998, 2001) e de alerta (Vigarello, 2001), (De Blic e Lemieux, 2005) evocam sentidos fortes e de grande negatividade, determinando, em certo sentido, a implementação nas sociedades modernas mundiais de práticas vigilantes face a inimigos desconhecidos e que atacam de forma imprevista. Para ir ao encontro deste estado de alerta permanente, as formas de mobilização colectiva 
produzidas com o propósito de estabilizar este espírito nas comunidades nacionais são feitas tendo em conta a necessidade de estas estarem atentas e dispostas a defender os ideais liberais.

Uma vez que a interpretação e o reconhecimento dos ideais liberais decorrem de matrizes políticas distintas, os argumentos políticos e filosóficos não são similares, e por isso, conflituais. Contudo, é preciso notar-se que estes conflitos são tolerados e até incentivados nas sociedades modernas e democráticas porque são a raiz do livre pensamento e do debate político, enquanto os outros conflitos emanam da violência, impedindo desta forma a circulação da argumentação contraditória (Boltanski, 1990) que está na base da construção das comunidades políticas modernas (Boltanski e Thévenot, 1991).

\section{Globalização, modernidade e a profissionalização das Forças Armadas: a tensão constante em torno dos valores e normatividades dentro e fora do enquadramento militar}

Neste sentido, defender os princípios fundadores da República e da Democracia cruzase com a defesa dos princípios fundadores de uma comunidade humana comum onde os princípios da liberdade política, da autonomia e da auto-realização coexistam com os princípios da ordem, da hierarquia e da disciplina agora extensíveis a todo o planeta. Isto significa que todas estas operações de sentido prático com que os cidadãos se vêem confrontados todos os dias face ao trabalho de representação realizado por distintos sistemas de representação da realidade política - do Estado aos meios de comunicação social - acontecem em sociedades pontuadas por múltiplas referências a valores e normatividades nem sempre coincidentes, quer em termos interpretativos (julgamentos fundamentados), quer em termos práticos (formas de actuação reflexiva).

Tomemos, por exemplo, os discursos que convocam a questão da multiculturalidade. Neste caso o que importa nomear de forma inequívoca é a importância conferida quer pelo conhecimento de si, quer pelo reconhecimento realizado pelos outros da autenticidade das culturas que coexistem num determinado espaço político. Ora esta autenticidade visa não só o reconhecimento público das diferenças (Taylor et al., 1998 [1994]) minoritárias, sejam quais forem as fontes dessa diferenciação, mas também o reconhecimento do seu estatuto de maioridade política.

Isto significa que a cada diferença socialmente reconhecida se deve dar a mesma voz e as mesmas oportunidades que são permitidas às configurações culturais e outras, que se apresentam como maioritárias no espaço público. Contudo, a este direito de cidadania já consagrado pelas cartas constitucionais os movimentos multiculturalistas requerem para estas culturas e práticas culturais distintas um princípio de excepcionalidade em virtude da pureza das suas características singulares e autênticas que é preciso preservar para a sua conservação no tempo e no espaço.

51 É sobretudo nestes últimos termos que a questão da singularidade e autenticidade cultural, veiculada pelos movimentos e discursos em prol do reconhecimento da diferenciação cultural, aparece ligada a uma das fontes de crítica social relativamente à extensão a todo o planeta dos valores e normatividades liberais gerados no quadro da civilização ocidental. Sob a voz de dirigentes políticos ligados a Estados independentes 
localizados em diferentes pontos do globo, a defesa da singularidade e autenticidade cultural é um instrumento que visa pôr em causa a legitimidade dos princípios que fundamentam aqueles valores e normatividades.

Por outro lado, estas mesmas clivagens são hoje sentidas no interior dos Estados modernos do Ocidente. Fruto dos fluxos migratórios crescentes ao longo das últimas 4 décadas do século passado, estas sociedades apresentam-se como sociedades onde coexistem grupos com distintas pertenças sociais e culturais em que a dimensão da nacionalidade (indicador de pertença a uma comunidade política com os mesmos direitos e deveres) engloba uma diferenciação que já não é exclusivamente social, de género ou etária, mas também étnica e religiosa. Apesar de estas últimas diferenças não serem uma novidade na actualidade, as últimas expressões da violência terrorista ocorridas em países do Ocidente potenciaram estas mesmas clivagens, mais em termos de representação política do que em termos das relações inter-individuais e intergrupais ${ }^{1}$.

53 A importância política assumida por estas clivagens culturais de raiz étnica vai ao encontro da questão do reconhecimento cultural autêntico e puro (Bauman, 1998). Este é muitas vezes um dos pontos de vista defendidos pelos porta-vozes destes colectivos. Contudo, este não é o único e exclusivo ponto de vista sobre esta questão. Existem outras formas de julgar estas diferenças, já não apostadas em fazer valer o reconhecimento da autenticidade e pureza cultural destes grupos, mas em chamar a atenção para a associação das desigualdades sociais a muitos indivíduos e famílias pertencentes a estes grupos étnicos. Neste último caso, o questionamento em volta do reconhecimento cultural na base do seu carácter genuíno é substituído pelo questionamento em volta do reconhecimento das injustiças de que são alvo, uma vez que alguns destes indivíduos e famílias não têm acesso, por processos de exclusão, aos bens públicos ligados às esferas de justiça implantadas nas sociedades modernas e liberais.

55 Em certo sentido, este questionamento também se deslocou para as Forças Armadas, uma vez que estas forças foram levadas a abrir o acesso aos seus contingentes a todos os indivíduos, independentemente dos seus espaços de pertença. A maior novidade residiu na incorporação das mulheres, que assim o desejam, nos diferentes corpos que compõem as Forças Armadas.

56 Neste sentido, a exclusividade masculina dá lugar a uma coabitação entre os dois géneros de uma forma cada vez mais extensa. Por outro lado, as mudanças surgidas nos critérios definidos para os processos de recrutamento não bastam para reduzir as contestações, uma vez que todo o princípio de exclusividade é posto em causa quer este resida à entrada das Forças Armadas, quer este exista ao longo da progressão da carreira militar, isto é, nos diferentes níveis hierárquicos que compõem o serviço efectivo dos quadros permanentes.

57 Na verdade, com o propósito de ir ao encontro dos princípios da equidade e da subida em generalidade, os processos de recrutamento não só se estendem às mulheres e a todos os grupos étnicos com nacionalidade portuguesa, como as oportunidades em termos de entrada no serviço efectivo dos quadros permanentes têm de ter em conta o género e a etnia, desde que estes indivíduos o desejem e cumpram todos os requisitos estabelecidos pelos concursos consignados pela lei. 
Confirmada a promessa de abertura das Forças Armadas a todos os indivíduos que disponham dos atributos exigidos por lei, sem qualquer tipo de discriminação ilegal e ilegítima, o princípio da equidade tem de coexistir com o princípio da eficiência e da eficácia ligada às novas finalidades e missões conferidas ao conjunto das forças militares. Com o objectivo de ir ao encontro deste último princípio, tendo em vista responder às novas incumbências cotejadas pela mais recente jurisdição militar, a dimensão numérica dos diferentes corpos tem de ser repensada.

Neste sentido, há uma tendência para a redução do número dos efectivos militares pertencentes à carreira, mas também há a necessidade de diminuir o contingente dos serviços efectivos dos regimes de voluntariado e de contrato. A exigência da profissionalização dos corpos militares condiciona o número de entradas voluntárias ou por contrato, apesar de a determinação do número concreto acabar por também depender das características das actividades ligadas a cada um dos três ramos das Forças Armadas, assim como das características das missões atribuídas a cada uma das forças que nelas se integram.

60 No entanto, a diminuição numérica das forças não responde inteiramente ao requisito da profissionalização. Para o cumprimento de mais esta promessa, os militares têm de conceder à instrução e formação profissional um lugar de enorme destaque.

61 Por um lado, a instrução visa a aquisição de competências técnicas indispensáveis para responder aos desafios dos meios tecnológicos postos ao serviço dos diferentes corpos militares. Por outro lado, os ganhos acrescidos de racionalidade prática cognitiva passam a ser determinantes para a concretização dos novos princípios estratégicos acoplados ao conceito de defesa nacional.

2 Desta forma, o significado atribuído à profissionalização das Forças Armadas depende da contingência de ocorrências exteriores que combinadas entre si conferem à profissão de militar algumas particularidades que convém identificar com alguma precisão. A criação simultânea de três serviços efectivos diferentes - quadros permanentes, contratados e voluntários - constitui um indicador a salientar.

Como a cada um destes serviços efectivos estão associadas lógicas particulares, dependentes do tempo de duração do vínculo profissional entre o militar e o Estado, a questão da fidelização dos candidatos ao serviço militar apresenta-se como uma questão central. Na verdade, a sua vinculação definitiva só acontece com a entrada nos quadros permanentes. Porém, as oportunidades de entrada neste tipo de serviço efectivo e permanente estão hoje mais condicionadas pelas razões atrás aduzidas.

4 Assim, as alternativas de fidelização ficam reduzidas ao regime contratual ou de voluntariado. Apesar de estas modalidades reforçarem a convergência entre a sociedade civil e as Forças Armadas, a criação de vínculos estáveis entre os militares contratados ou em regime de voluntariado não só fica a depender das oscilações do mercado escolar e de emprego como também fica sujeita à operacionalização do sistema de incentivos, quer os de natureza pecuniária, quer os de natureza da formação profissional visando o seu reingresso futuro noutros mercados de emprego (Boene, 2003) existentes, mas fora do universo militar.

65 Porém, o efeito na procura dos lugares disponibilizados por cada um dos três ramos das Forças Armadas dos fluxos existentes (e oscilantes) nos mercados atrás referidos não esgota todo o factor contingencial que se depreende daquela relação. Outros processos contingenciais interferem naquela relação, nomeadamente as contingências 
decorrentes da correlação de forças entre a "fronteira de soberania" e a "fronteira de vulnerabilidade" (Carrilho, 1998: 70), extraordinariamente dependente da "gestão" política dos conflitos, quer os eminentemente militares, quer outros que resultam de movimentos de reivindicação de soberania, de reconhecimento cultural genuíno e religioso, etc.

Face a estas incertezas, tornam-se decisivas as tarefas de identificar e tipificar as expectativas produzidas pelos jovens em geral, e pelos jovens potencialmente destinados a ingressar nas Forças Armadas, em particular. Uma articulação mais ajustada entre as expectativas desejadas por estes jovens e as expectativas satisfeitas em contexto militar pode eventualmente contribuir para melhorar os processos de fidelização, estimulando desta forma o recrutamento profissional de indivíduos com uma formação escolar e técnica mais valorizada. Uma vez que as exigências tecnológicas variam consoante os ramos e os postos militares, e que por isso as tarefas de execução tecnológica e de combate podem não ser valorizadas de igual modo pelos jovens que potencialmente se interessam pela vida militar, a elevação da qualificação do posto a oferecer ao exterior (mesmo aquele que se liga ao combate) permite diminuir o efeito do risco da construção de identidades negativas entre os jovens recrutas (Léger, 2003).

Conhece-se hoje a centralidade do corpo (Resende, 1999) nas sociedades modernas. Utilizado por distintos discursos - uns ligados à estética, outros ligados à saúde -, a gestão corporal apresenta-se como um ícone identitário dos grupos juvenis. Por outro lado, o lugar de destaque detido pelo corpo pode ser pensado no quadro dos processos de individuação inscritos na modernidade liberal alargada (Wagner, 1996) ou na modernidade reflexiva como Giddens (1992 [1990]) prefere designá-la.

Seja qual for a designação escolhida para a definição da modernidade contemporânea, a questão do self liga-se a uma procura permanente do indivíduo moderno sobre as suas potencialidades, as suas limitações, os seus desejos (mesmos os do foro da intimidade) e as suas aspirações. Isto significa que a dimensão centralizada sobre o ego, nas suas dimensões mais subjectivas e emocionais, conduz o indivíduo a uma busca permanente da sua auto-identidade. Mas, como Grácio sustenta, o investimento pessoal na autoidentidade relaciona-se também com o "actual estádio das relações entre as esperanças e as oportunidades de mobilidade ascendente (...)" (Grácio, 1997: 147), que contribuem quer para a desestruturação (e recomposição sobre outras modalidades e suportada por outros dispositivos) das classes sociais como expressões políticas colectivas, quer para a aceleração das insatisfações individuais e colectivas face às promessas de progresso e de bem-estar individual e colectivo, e seus obstáculos correlacionados, emanadas pelos discursos mais representativos dos projectos políticos da modernidade.

Neste quadro geral em que a multiplicidade de referências e de valores se alarga a grande parte dos indivíduos modernos (independente da idade e do género) que encontram neste contexto a justificação optimizada de uma procura urgente do seu projecto individual, muitas vezes indagando o seu norte nos movimentos de auto-ajuda ou nos conselhos difundidos por diferentes especialistas (psicólogos, psicanalistas e psiquiatras, entre outros), muitos jovens encontram neste domínio o terreno profícuo para a defesa dos estilos de vida que configuram as suas auto-identificações com os valores culturais que perfilam aqueles que partilham os mesmos interesses. Na verdade, a estruturação destes ambientes juvenis parece ocorrer num contexto em que "cada qual se vira para si próprio, não no sentido solipsista, mas no sentido de uma soberana, 
consciente e informada administração da sua idiossincrasia, de descoberta da própria verdade, construindo-a num ambiente cultural em que o pluralismo de modelos e de opções ganha crescente legitimidade" (ibidem: 147).

Assim, este novo "investimento de forma" de si e categorial (Thévenot, 1986) na individualidade moderna parece ir em sentido contrário aos "valores universalistas e de realização pessoal" em que o actor individual "voltado para a ascensão social" era "capaz de diferir as satisfações imediatas e de sacrificar assim talvez uma parte de si" (Grácio, 1997: 149), para apostar de uma forma ofensiva, optimista e confiante no futuro que se avizinhava a qualquer instante. Para Grácio este modelo de actor reduzido a uma caricatura social, pela sua frouxa representatividade em virtude da existência de um contexto socioeconómico que diminui as oportunidades sociais, é substituído por outros dois modelos de actores que coexistem com o primeiro: de um lado o modelo de actor descrente e desencantado moldado pela "nova economia psicológica" (ibidem) e do outro o modelo de actor "cultor e em busca de si próprio e da sua efectividade, voltado para os novos valores da vida pessoal e relacional" (ibidem).

71 Mais do que discutir a conformidade destes modelos relativamente às suas potencialidades heurísticas, a tipificação do conceito de actor construída por Grácio tem a qualidade de chamar a atenção da interpretação sociológica para a relevância da multiplicidade de referências em termos de valores e normatividades, mas também de deslocar o olhar exclusivo do actor para os regimes em que estes se envolvem quando se confrontam com diferentes controvérsias, dilemas, disputas ou mesmo conflitos (Thévenot, 2006). Aliás, a convocação desta questão não é nova na Sociologia, porque são vários os autores que apresentam esta questão como fundamental para a definição sociológica do conceito de indivíduo moderno (Singly, 2000; Martuccelli, 2002), mas cuja concepção se completa quando a esta figura moderna se associa a sua propensão para agir no plural, enquadrado nos cenários onde se desloca no quotidiano (Dodier, 2003; Thévenot, 2006).

Na senda das discussões à volta do conceito de actor e de acção social importa destacar que estes modelos coexistem nas sociedades contemporâneas, importando mais afinálos no âmbito de situações concretas, tendo em conta a importância de apreender os indivíduos e as suas acções "tanto nas suas dimensões mais interiores como nas suas dimensões mais públicas e materiais", as duas inseridas "num trajecto particular" (Martuccelli, 2002: 561). É por isso que os estudos sobre o Dia de Defesa Nacional, ou estudos mais aprofundados sobre os mecanismos utilizados pelos jovens para se aproximarem ou se afastarem dos rituais castrenses ou ainda as investigações sobre as modalidades de socialização operadas no interior de diferentes corpos militares, quer através da adopção da figura do voluntário ou da figura do contratado, apresentam-se como importantes, pois tornam possível acumular informações pertinentes para conceber e interpretar o lugar das Forças Armadas nas sociedades modernas, mas também para equacionar os desafios a que estas estão hoje sujeitas para responder a novos problemas ligados, muitas vezes, a velhas questões internas e transnacionais.

73 Os desafios levantados pela multiplicidade de referências, de valores e de normatividades estão também presentes nos processos de transição dos jovens, quer para a vida adulta, quer para a vida activa. Na verdade, nas sociedades modernas os percursos escolares dos jovens tendem a ser cada vez mais prolongados no tempo, uma vez que a certificação numa formação adequada passa a constituir uma carta de apresentação importante, quer em termos estatutários e de pertença identitária, quer 
em termos de competição no âmbito dos mercados de emprego cada vez mais fragmentados. Por outro lado, os contextos laborais já não primam pela sua estabilidade temporal, o que implica uma outra postura face ao trabalho, de maior flexibilidade e de maior disponibilidade por parte da mão-de-obra, em particular nas situações laborais mais precárias.

O reforço no investimento escolar e na formação profissional, muitas vezes associados a vinculações laborais muito incertas, tende a contribuir para que os jovens protelem as suas saídas das casas dos pais. Desta forma os processos de autonomia e de autorealização confinados a uma formação escolar e/ou formação profissional prolongadas coexistem com os laços de dependência funcional na casa dos seus progenitores. Outras vezes acontecimentos imprevistos decorrentes da natureza contingente das situações em que se encontram envolvidos (uma gravidez inesperada, desemprego, a morte de um familiar, etc.) levam muitos jovens a reorientar os seus planos, os seus investimentos pessoais e interpessoais desenvolvendo outras modalidades de composição, fazendo intervir, por exemplo, regimes de envolvimento da acção plurais ajustáveis às novas situações (im)previstas.

\section{Em jeito de conclusão: notas finais}

Os retratos possíveis aqui salientados, e recompostos a partir dos trajectos históricos da modernidade, levantam sérios problemas que exigem, como atrás referimos, uma reflexão aprofundada e continuada da parte dos responsáveis pelos processos de recrutamento militar. Como é do conhecimento informado, a ampla esfera militar continua fiel a um conjunto de valores e de normatividades que orientam a prestação do seu serviço à sociedade.

Neste sentido, "a defesa nacional tem por objectivo garantir a independência nacional, a integridade do território e a liberdade e a segurança das populações contra qualquer agressão ou ameaças externas" (Resolução do Conselho de Ministros n.. 6/2003, 279). Caucionada que está a defesa do Estado democrático pelas Forças Armadas, estas contribuem para assegurar "a continuidade de Portugal enquanto país europeu, de centralidade atlântica e vocação universalista" (ibidem). Ora a prossecução destes propósitos transforma as Forças Armadas num pilar vital para a sobrevivência do País como nação independente e soberana, mas também respeitadora da carta constitucional democrática que consagra os direitos e os deveres de todos os cidadãos, $\mathrm{e}$ ainda atenta aos desafios que a integração europeia impõe ao País.

No quadro de uma soberania que em parte já é partilhada com a União Europeia, mas sobretudo com a tensão crescente entre a "fronteira soberana" e a "fronteira da vulnerabilidade", em virtude das conflitualidades ocorridas desde 11 de Setembro de 2001, as Forças Armadas continuam a deter um lugar de destaque na coesão social e na afirmação de Portugal no mundo. A preservação da representação militar como esteio da República e da Democracia reserva-lhe a apresentação de alguns requisitos de natureza regulamentar, que exigem dos seus membros, quer os do quadro permanente, quer os voluntários e os contratados, o respeito por um conjunto de valores e de normatividades.

Face a estes propósitos, os responsáveis pelo actual serviço de recrutamento militar não podem descurar os contextos de onde saem os potenciais jovens candidatos à vida castrense, em particular os ambientes culturais pontuados com a pluralidade de 
referências identitárias que se cruzam com a pluralidade dos valores e normatividades que enquadram os seus estilos de vida. Mesmo considerando a existência de pontos de vista positivos sobre a instituição militar entre os jovens inquiridos, e conhecendo que estes lhe reconhecem legitimidade na sua forma de actuação, as prováveis tensões entre valores e normatividades distintas não devem ser afastadas do horizonte das suas reflexões sobre este assunto.

Por outro lado, as suas expectativas de partida sobre as actividades e missões das Forças Armadas podem não coincidir inteiramente com a experiência que resulta da efectiva incorporação. Neste sentido, para se preservar como uma fonte legitimadora, quer entre os jovens e outros indivíduos potencialmente recrutáveis, quer entre os restantes cidadãos, o poder militar organizado tem de porfiar lado a lado com outras instituições, como por exemplo a escola e o mercado, com o objectivo de se tornar cada vez mais atractiva. Continuar a ser precursora na inovação tecnológica, na sua organização e nos processos de formação interna passa a constituir uma missão importante, uma vez que só assim é que consegue mobilizar os jovens conquistando para as suas forças os mais qualificados do ponto de vista escolar, mas também profissional.

\section{BIBLIOGRAFIA}

ABBOTT, A. (1988), The System of Professions. An Essay on the Division of Expert Labor, Chicago e Londres, The University of Chicago Press.

BAUMAN, Z. (1998), o Mal-Estar da Pós-Modernidade, Rio de Janeiro, Jorge Zahar Editores.

BAUMAN, Z. (2001), Modernidade Líquida, Rio de Janeiro, Jorge Zahar Editores.

BECK, U. (2001), La société du Risque. Sur la voie d'une autre modernité, Paris, Flammarion.

BECK, U.; A. Giddens e A. Lash (2000 [1994]), Modernização Reflexiva. Política, Tradição e Estética no Mundo Moderno, Oeiras, Celta.

BOENE, B. (2003), “La professionnalisation des armées: contexte et raisons, impact fonctionnel et sociopolitique", Revue Française de Sociologie, 44-4, pp. 547-693.

BOLTANSKI, L. (1990), L'amour et la justice comme compétences. Trois essais de sociologie de l'action, Paris, Éditions Métailié.

BOLTANSKI, L. (2001), “A Moral da Rede? Críticas e Justificações nas Recentes Evoluções do Capitalismo”, Forum Sociológico, 5/6, pp. 13-35.

BOLTANSKI, L. e L. Thévenot (1991 [1987]), De la justification. Les économies de la grandeur, Paris, Gallimard.

BOLTANSKI, L. e È. Chiapello (1999), Le nouvel esprit du capitalisme, Paris, Gallimard.

CARRILHO, M. (1998), Portugal no Contexto Internacional. Opinião Pública, Defesa e Segurança, Lisboa, Edições Cosmos/Instituto de Defesa Nacional. 
DE BLIC, D. e C. Lemieux (2005), “Le scandale comme épreuve. Éléments de sociologie pragmatique",

Politix. Revue des Sciences du Politique, 71, pp. 9-38.

DODIER, N. (2003), “O Espaço e o Movimento do Sentido Crítico”, Forum Sociológico, 13/14, (II Série), pp. 239-277.

ELIAS, N. (1989), O Processo Civilizacional - Investigações sociogenéticas e psicogenéticas I Volume Transformações do comportamento das camadas superiores seculares do Ocidente, Lisboa, Publicações Dom Quixote.

ELIAS, N. (1990), O Processo Civilizacional - Investigações sociogenéticas e psicogenéticas II Volume Transformações da sociedade. Esboço de uma teoria da civilização, Lisboa, Publicações Dom Quixote.

EVETTS, J. (2003), "Explaining the construction of professionalism in the military: history, concepts and theories”, Revue Française de Sociologie, 44-4, pp. 759-776.

GIDDENS, A. (1992 [1990]), Consequências da Modernidade, Oeiras, Celta Editora.

GRÁCIO, S. (1997), Dinâmicas da Escolarização e das Oportunidades Individuais, Lisboa, Educa.

LÉGER, J.-F. (2003), “Pourquoi des jeunes s'engagent-ils aujourd'hui dans les armées”, Revue Française de Sociologie, 44-4, pp. 713-734.

MARAVALL, J. M. (1972), La Sociologia de lo Posible, Madrid, Siglo XXI.

MARTUCCELLI, D. (2002), Grammaires de l'individu, Paris, Gallimard.

RESENDE, J. M. (1999), “A Construção Social do Corpo nas Sociedades de Modernidade Tardia: Disposições Corporais Distintivas e a Corporalidade como Recurso Mobilizado nas Relações e Trajectórias Sociais", Forum Sociológico, 1-2 (II Série), pp. 9-40.

SINGLY, F. (2000), o Eu, o Casal e a Família, Lisboa, Publicações Dom Quixote.

TAYLOR, C.; K. A. Appiah et al. (1998 [1994]), Multiculturalismo. Examinando a política de reconhecimento, Lisboa, Instituto Piaget.

THÉVENOT, L. (1986), “Les investissements de formes”, in L. Thévenot (ed.), Conventions économiques, Paris, Presses Universitaires de France, pp. 21-71.

THÉVENOT, L. (2006), L'action au pluriel, sociologie des régimes d'engagement, Paris, Éditions La Découverte.

VigARELLO, G. (2001), História das Práticas de Saúde. A saúde e a doença desde a Idade Média, Lisboa, Editorial Notícias.

WAGNER, P. (1996), Liberté et Discipline. Les deux crises de la modernité, Paris, Éditions Métailié.

\section{ANEXOS}

Documentos

Lei n. ${ }^{\circ}$ 174/99 de 21 de Setembro de 1999

Lei n. ${ }^{\text {111/91 de }} 29$ de Agosto de 1991

Decreto-Lei n.. 289/2000 de 14 de Novembro de 2000

Resolução do Conselho de Ministros n.ำ6/2003 de 20 de Janeiro 


\section{NOTAS}

1. A natureza política das clivagens culturais de raiz étnica assume diferentes configurações. Não se pretende neste texto menorizar as clivagens que resultam de comportamentos xenófobos de carácter rácico. Face aos movimentos fundamentalistas de carácter religioso, étnico ou culturalista, as reflexões sobre o reconhecimento cultural intentam neste texto fechar o ângulo de análise sobre este problema político, sem querer ignorar a existência da conflitualidade ligada às diferenças raciais, muitas vezes espoletadas pelo reconhecimento da parte da minoria étnica de um tratamento desigual e não respeitoso por parte dos outros que pertencem à maioria da população. Ora muitas vezes as disputas de carácter rácico são, em muitas situações, constitutivas das relações inter-individuais e intergrupais.

\section{RESUMOS}

As Forças Armadas portuguesas entram numa nova fase na sua história recente com a oficialização do Dia da Defesa Nacional. Este evento nacional marca o fim da obrigatoriedade inscrita na lei de Serviço Militar. Através deste artigo o seu autor analisa sociologicamente as consequências da entrada de um novo serviço militar e as novas formas de recrutamento à disposição das Forças Armadas portuguesas. Por outro lado, as bases de enquadramento normativo que enquadram estas alterações são alimentadas por um novo conceito de estratégia de defesa nacional, tendo em conta o lugar do País e das suas Forças Militares, quer na Europa, quer em termos do processo de globalização em curso. Finalmente, o processo de profissionalização destas forças coloca novos desafios a cada um dos três ramos que compõem as Forças Armadas Portuguesas.

The Portuguese Armed Forces enter a new Era of its recent history with the formalization of the National Defence Day. This national event marks the end of the compulsory Military Service. Through this article, its author sociologically analyses the consequences of the emergence of a new military service as well as the new recruitment means available to the Portuguese Armed Forces. On the other hand, the bases of the new normative framework which encompass these changes are fed by a new concept of national defence strategy, taking into account the country's and its Military Forces' positioning both in Europe and in the context of the ongoing globalization. Lastly, the professionalization process of these forces places new challenges to each of the three services which compose the Portuguese Armed Forces.

\section{ÍNDICE}

Keywords: National Defence Day, national defence strategy, globalization and Armed Forces professionalization

Palavras-chave: Dia da Defesa Nacional, estratégia de defesa nacional, globalização e profissionalização das Forças Armadas 
AUTOR

JOSÉ MANUEL RESENDE

Departamento de Sociologia da FCSH-UNL, CesNova josemenator@gmail.com 